\title{
Clinical evaluation of diaphyseal femoral fractures operated in lateral decubitus position with interlocking nail
}

\author{
Syed S. M. Haque ${ }^{1 *}$, Alaf A. Pathan', Ansari M. A. Aziz' ${ }^{1}$ Ayesha Saba²
}

\begin{abstract}
${ }^{1}$ Department of Orthopaedics, ${ }^{2}$ Department of General Surgery, Government Medical College, Aurangabad, Maharashtra, India
\end{abstract}

Received: 24 August 2021

Revised: 31 August 2021

Accepted: 01 September 2021

\section{*Correspondence:}

Dr. Syed S. M. Haque,

E-mail: mashuduls@gmail.com

Copyright: ( ) the author(s), publisher and licensee Medip Academy. This is an open-access article distributed under the terms of the Creative Commons Attribution Non-Commercial License, which permits unrestricted non-commercial use, distribution, and reproduction in any medium, provided the original work is properly cited.

\begin{abstract}
Background: The diaphyseal fractures of femur in adults are conventionally treated in supine position on traction table, which carries risk of compartment syndrome, pudendal nerve palsy, whereas in lateral decubitus position these complications can be avoided with additional advantage of easy access to greater trochanter particularly in obese patients. The aim of this study is to evaluate outcomes of femur diaphyseal fractures treated with intramedullary interlocking nail in lateral decubitus position.

Methods: In this study 40 patients with femur diaphysea fractures were treated with intramedullary interlocking nail in lateral decubitus position, were studied for a period of 9 months from September 2019 to May 2020.

Results: At the end of our study of 40 patients, outcome is graded according Thoresen's criteria where $22(55 \%)$ patients had excellent results with full, pain-free, function of the extremity and 11 (27.5\%) patients had good result; 10 patients had range of motion $120^{\circ}$ and shortening of femur by 1.5 was observed in 1 patient. There were $6(15 \%)$ patients with fair result; with range of motion $90^{\circ}$ and 1 poor result $(2.5 \%)$ had non-union with range of motion $<90^{\circ}$.

Conclusions: Fixation of femur diaphyseal fracture in lateral decubitus position leads to easy access to the proximal femur making it easy to establish an entry point for an intramedullary device and it significantly eliminates the complications caused by other conventionally used methods.
\end{abstract}

Keywords: Lateral decubitus position, Femur shaft fracture, Interlocking nail

\section{INTRODUCTION}

The femoral shaft fractures in adults are preferably treated with closed intramedullary nailing. ${ }^{1}$ Closed reduction is a critical component of the procedure and fracture table is used to generate longitudinal traction to achieve closed reduction and maintain the reduction during the operative fixation. ${ }^{2,3}$ The complications reported following use of traction on a fracture table are pudendal nerve palsy, compartment syndrome, and skin sloughs of the perineum. ${ }^{4-6}$ Intramedullary nailing of femur without a fracture table has been reported. ${ }^{7-10}$ Compared with fracture table traction, manual traction for intramedullary nailing of isolated fractures of the femoral shaft has been shown to decrease operative time and improve the quality of the reduction. ${ }^{11}$

Femoral nailing can be performed in both supine and lateral position. ${ }^{12}$ The supine position is physiologic and convenient to the anesthetist and is preferred if patient also have cervical spine injury, ipsilateral lower extremity fracture and severe pulmonary compromise. But access to greater trochanter is somewhat limited in supine position, particularly in large or obese patients in whom lateral position is preferred. ${ }^{13}$ Fluoroscopy is used extensively during locked intramedullary nailing, which increases the intra-operative radiation exposure. ${ }^{14}$ This study aims to evaluate the outcome in patients of femoral shaft fractures 
who had intramedullary nailing in lateral decubitus position.

\section{METHODS}

It is a prospective observational study of 40 patients with diaphyseal fractures of femur admitted at department of orthopaedics, Government Medical College, Aurangabad, Maharashtra meeting the inclusion and the exclusion criteria (as given below) during the study period September 2019-May 2020.

\section{Study topic}

Clinical evaluation of diapyseal femoral fractures operated in lateral decubitus position for interlocking nail.

\section{Method of collection of data}

\section{Inclusion criteria}

Patients with age group $>18$ years and diaphyseal femoral fractures (all types of closed/open diaphyseal variants).

\section{Exclusion criteria}

Patients with grade-III Gustilo Anderson open fracture, polytrauma, associated with head injury, pathological fractures, old fracture non-union and delayed union; and preexisting stiffness, deformity, congenital anomalies of the involved limb were excluded.

\section{Methodology}

When the patient with femur shaft fracture was admitted to hospital all the necessary clinical details were recorded in study proforma prepared with for this study. Ethical approval was taken from the medical college appointed approved local ethics committee for the study, before initiation of this study and review with the committee was done periodically. Clinical and radiological examination was done followed by skin traction and limb elevated over Bohler Braun splint or Thomas' splint was used for the effected limb and the facture pattern was classified. Routine investigations were done, haemoglobin percentage, fasting blood sugar, pre-op serology. Electrocardiography (ECG), 2D echocardiography (echo) as needed. Distal neurovascular status was assessed. Instruments required were checked and sterilized beforehand.

\section{Counselling and consent}

All patients and their relatives were counselled to their satisfaction in their own language about the aim of this study, surgery, advantages and disadvantages, alternatives, possible complications and outcome of various procedures and informed consent were taken. After due consent and medical or anaesthetic clearance, the patients were posted for surgery.

\section{Operation technique}

\section{Anaesthesia and patient positioning}

Patient is kept under general or spinal anesthesia.

\section{Lateral decubitus positioning of patient}

This technique is applicable to all types of femoral shaft fractures. It is especially advantageous in obese patients, as the fat appendages tend to displace toward the floor and away from the starting point.

Patient with the fractured side up is placed on a radiolucent flat top table in a lateral decubitus position. Side supports were used to hold the patient in position. Fluoroscopic compatibility of the position was assessed for any overlapping and obstructions for a clear view. The entire visualization of the thigh was done fluoroscopically followed by draping.

An incision was taken 5 to $10 \mathrm{~cm}$ proximal to the tip of greater trochanter in lateral decubitus position with the hip flexed the damage to the gluteus medius was minimized by identifying its posterior edge. Proximal canal entered with entry awl by fluoroscopic visualization in anteroposterior (AP) and lateral views. A bulb-tipped guide wire was then passed into the proximal fragment.

Fracture reduction was done under fluoroscopic guidance. The guide wire was further advanced through the distal fragment approximately $5 \mathrm{~mm}$ proximal to the intercondylar notch and centering was done.

Sequential reaming was done after confirming the nail size and diameter the nail was connected to the standard insertion handle and introduced in the proximal fragment and was driven across the fracture site with attention given to alignment, rotation and length of the thigh. Femoral rotational alignment was analysed by rotating the flexed leg to 10 to 15 degrees internally on the thigh. The locking of the nail was done as per manufacturer recommendations. The proximal and distal locking is performed from lateral to medial and is facilitated by raising the $\mathrm{C}$-arm as high as possible. Wound closure was done in layers. Compression dressing done and distal neurovascular status was checked.

\section{Post-operative care}

Post-operative radiographs were assessed and the wound was inspected on $3^{\text {rd }}$ and $4^{\text {th }}$ post-operative day. Exercises were started from the next day of surgery. Appropriate analgesics and antibiotics were given for first five days and advised to come for suture removal on $14^{\text {th }}$ day. Patient was discharged with a walker and advise to be followed at home. Non-weight bearing ambulation on $5^{\text {th }}$ to $7^{\text {th }}$ day and 
partial weight bearing started at 4 weeks. Full weight bearing started by eight to twelve weeks depending on fracture configuration and radiological callus formation.

\section{Follow up}

Assessment at regular intervals was done at 2, 4, 6, 8 and 12 weeks. At each follow-up visit, patient was evaluated clinically, radiologically if needed and complications were noted. A detailed observation was recorded using attached study proforma.

\section{Statistical analysis}

Quantitative data is presented with the help of mean and standard deviation. Comparison among the study groups is done with the help of unpaired t-test as per results of normality test. Qualitative data is presented with the help of frequency and percentage table. Association among the study groups is assessed with the help of Chi-square test. ' $\mathrm{P}$ ' value less than 0.05 is taken as significant.

\section{Statistical analysis}

Quantitative data is presented with the help of mean and standard deviation. Comparison among the study groups is done with the help of unpaired t-test as per results of normality test. Qualitative data is presented with the help of frequency and percentage table. Association among the study groups is assessed with the help of Chi-square test. ' $\mathrm{P}$ ' value less than 0.05 is taken as significant.

\section{Pearson's Chi-squared test}

$X^{2}=\sum_{i=1}^{n} \frac{\left(O_{i}-E_{i}\right)^{2}}{E_{i}}$

Where, $\mathrm{X}^{2}=$ Pearson's cumulative test statistic, $\mathrm{O}_{\mathrm{i}}=$ an observed frequency; $\mathrm{E}_{\mathrm{i}}=$ an expected frequency, asserted by the null hypothesis; and $\mathrm{n}=$ the number of cells in the table.

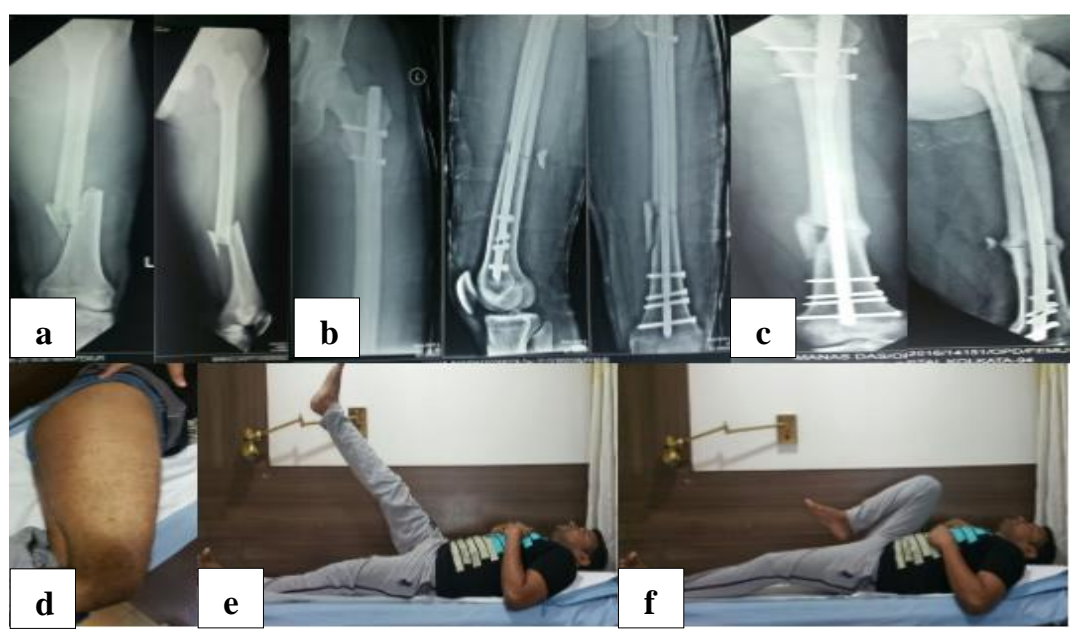

Figure 1: (a) Preoperative X-ray showing diaphyseal comminution, (b) post-op X-ray good reduction, (c) post-op 3 months X-ray, (d) post-op wound healed, (e) active straight leg raising post op 3 months, and (f) active hip and knee flexion post-op 3 months.

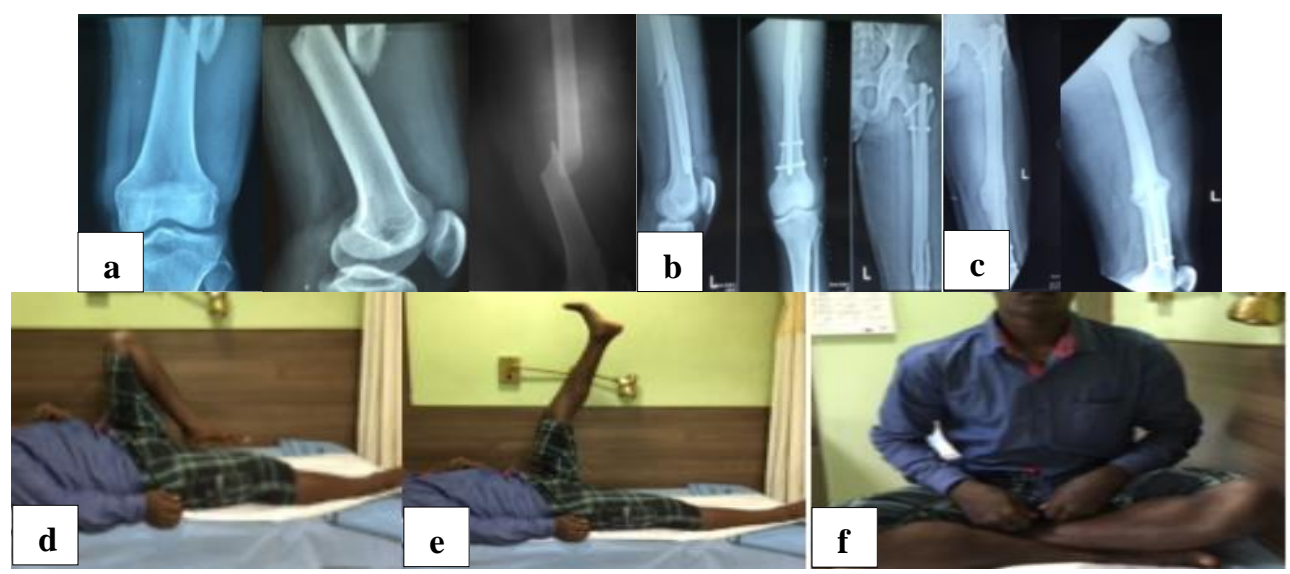

Figure 2: (a) Pre-operative X-ray showing diaphyseal comminution, (b) postoperative X-ray good reduction, (c) post op 3 months X-ray, (d) active hip and knee flexion post op 3 months, (e) active straight leg raising post-op 3 months, and (f) sitting crossed leg. 


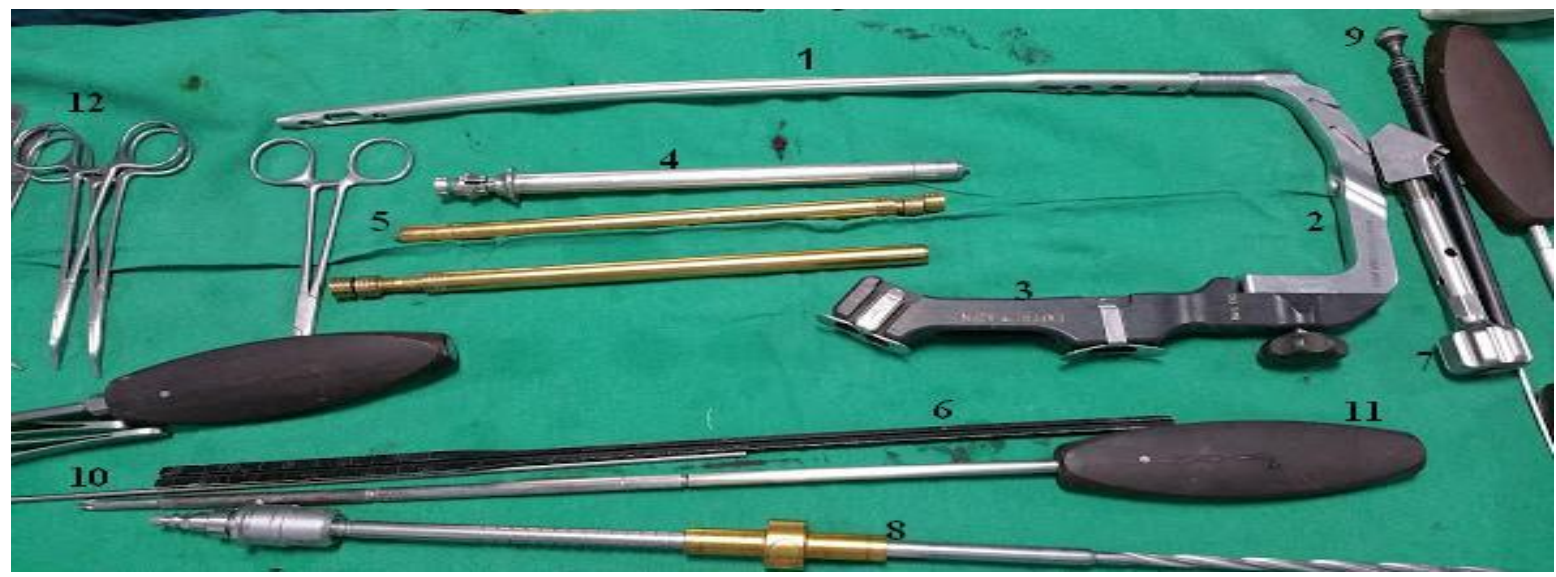

Figure 3: Instruments used for surgery - (1) intramedullary nail, (2) standard insertion handle, (3) aiming arm for Antegrade standard locking, (4) protection and drill sleeve with trocar, (5) locking sleeves, (6) direct measuring device, (7) insertion handle, (8) drill for cervical hip screw, (9) depth gauge, (10) drill bit, (11) star drive screw driver, and (12) artery forceps.

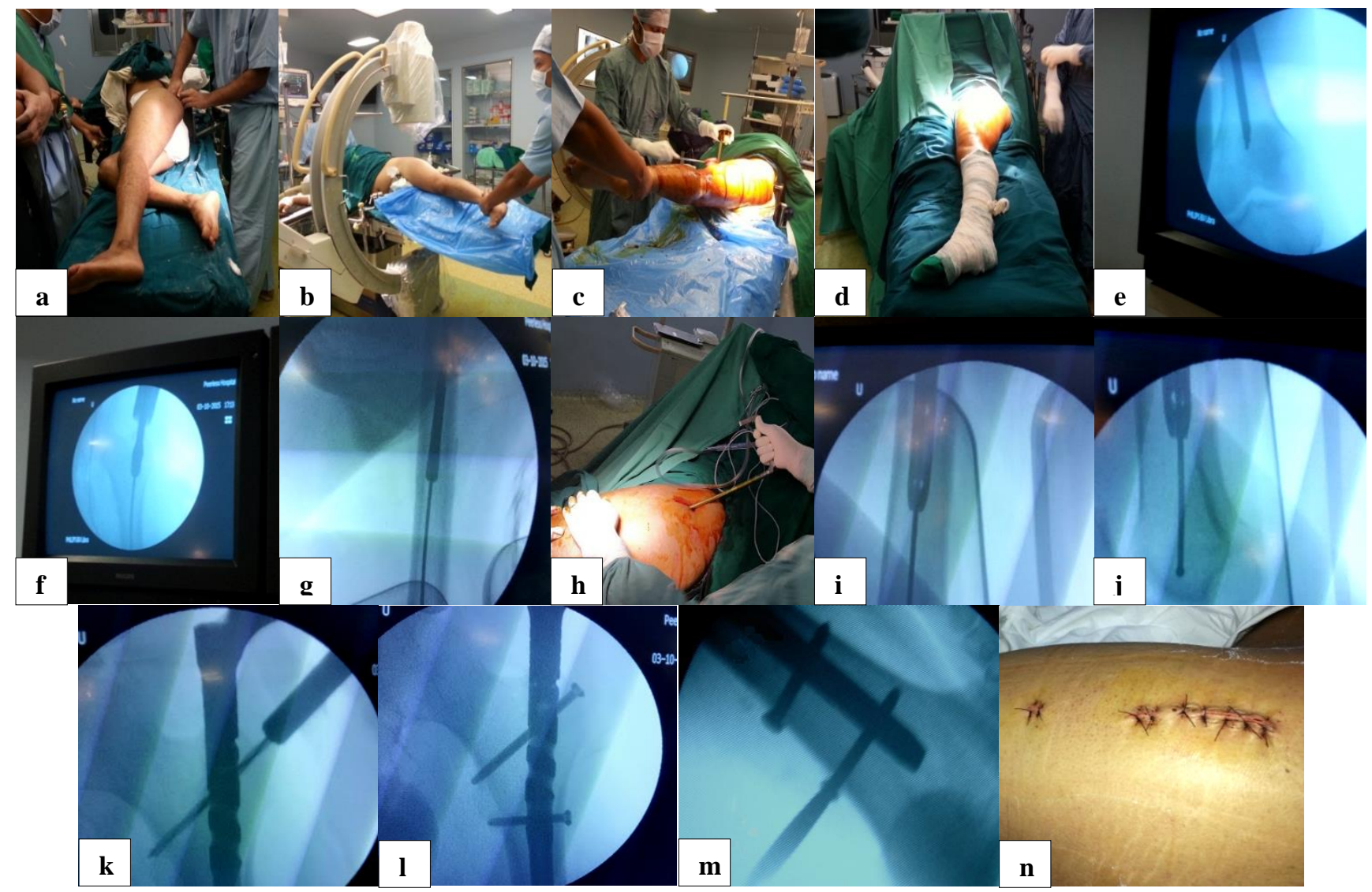

Figure 4: Intra operative photos (a) Position, (b) fluroscopy, (c) painting, (d) draping, (e) entry point, (f) entry point AP view, (g) canal reaming, (h) nail insertion, (i) crossing the distal fragment, (j) assessing extent, (k) proximal locking - drilling, (l) proximal locking, (m) distal locking, and (n) closure.

Results were graphically represented where deemed necessary.

Appropriate statistical software, including but not restricted to Microsoft (MS) excel, statistical package for the social sciences (SPSS) version 20 was used for statistical analysis. Graphical representation was done in MS excel 2010.

\section{RESULTS}

The present study was conducted over 40 adults for evaluation of diaphyseal fracture femur treated with 
intramedullary interlocking nail in lateral decubitus position from September 2019 to May 2020 at Department of Orthopaedics, Government Medical College, Aurangabad, Maharashtra. The following observations were made in our study.

Table 1: Classification of femur shaft fracture (AO type).

\begin{tabular}{|lll|}
\hline AO type & No. of patients & $\%$ \\
\hline A & 14 & 35 \\
\hline B & 24 & 60 \\
\hline C & 2 & 5 \\
\hline Total & 40 & 100 \\
\hline
\end{tabular}

Table 2: Intra-operative results- fluoroscopy time.

\begin{tabular}{|l|l|l|}
\hline Fluoroscopy time (min) & No. of patients & $\%$ \\
\hline $\mathbf{2 . 5}-\mathbf{3}$ & 16 & 40 \\
\hline $\mathbf{3 - 3 . 5}$ & 6 & 15 \\
\hline $\mathbf{3 . 5}-\mathbf{4}$ & 18 & 45 \\
\hline Total & 40 & 100 \\
\hline $\begin{array}{l}\text { Mean fluoroscopy time } \\
\text { (min) }\end{array}$ & 3.16 & \\
\hline
\end{tabular}

Table 3: Intra-operative results - operative time.

\begin{tabular}{|l|l|l|}
\hline Operative time (min) & No. of patients & $\%$ \\
\hline $\mathbf{8 0 - 1 0 0}$ & 22 & 55 \\
\hline $\mathbf{1 0 0 - 1 2 0}$ & 18 & 45 \\
\hline Total & 40 & 100 \\
\hline $\begin{array}{l}\text { Mean operative time } \\
\text { (min) }\end{array}$ & 97.25 & \\
\hline
\end{tabular}

Table 4: Intraoperative problems.

\begin{tabular}{|lll|}
\hline Intraoperative problems & No. of patients & $\%$ \\
\hline Difficulty in entry point & 1 & 2.5 \\
\hline Difficulty in reduction & 2 & 5 \\
\hline Impaction of nail & - & - \\
\hline Intraoperative fracture & 1 & 2.5 \\
\hline Persisting deformity & - & - \\
\hline
\end{tabular}

Table 5: Commencement of non-weight bearing (NWB) ambulation.

\begin{tabular}{|lll|}
\hline Non-weight bearing (days) & No. of patients & $\%$ \\
\hline $\mathbf{1 - 3}$ & 36 & 90 \\
\hline$>\mathbf{5}$ & 4 & 10 \\
\hline
\end{tabular}

Table 6: Complications.

\begin{tabular}{|lll|}
\hline Complications & No. of patients & $\%$ \\
\hline Delayed union & 1 & 2.5 \\
\hline Non-union and ROM & 1 & 2.5 \\
\hline Shortening 1.5 cm & 1 & 2.5 \\
\hline Deformity ER + valgus & 1 & 2.5 \\
\hline
\end{tabular}

\section{DISCUSSION}

Lateral decubitus position obviates the need for fracture table, making it easier to establish an entry point for an intramedullary device. The complications reported following use of traction on a fracture table are pudendal nerve palsy, compartment syndrome and skin sloughs of the perineum.

In our present study of 40 patients the purpose of the study was evaluation of diaphyseal

fracture of femur in adults treated with intramedullary interlocking nail in lateral decubitus position. The data collected in our study is assessed, analysed and compared to other series and the results are evaluated.

In our study transverse (45\%) was most common fracture pattern followed by Oblique fractures (25\%), Obliquetransverse fractures $(20 \%)$ and spiral fractures (10\%). Most common pattern of fracture reported in the study of Deepak et al. ${ }^{14}$ was comminuted and transverse fractures $(63.33 \%)$. Our study is closely similar to the series of Deepak et al, comminuted(40.6\%), Butterfly (21.1\%) and Transverse $(16.4 \%)$ in 293 patients in series KlemmBorner. ${ }^{14,15}$ In our study of 40 patients, $95 \%$ patients achieved union and the average time for healing of the fracture was 20.9 weeks. Dynamisation was required in 2 patients. Average time for dynamisation was 6.5 weeks with mean healing time of 29.4 weeks. White et al observed union rate of $99 \%$ and healing time of 16 weeks in his study. ${ }^{16}$

In our study $18(45 \%)$ patients had Fluoroscopy time of 3.5-4 mins followed by $16(40 \%)$ patients with Fluoroscopy time of 2.5-3 mins and $6(15 \%)$ patients with Fluoroscopy time of 3-3.5 mins. The mean Fluoroscopy time was 3.16 mins. Ha et al observed that mean fluoroscopy time was 3.08 mins. ${ }^{17}$ In our study $22(55 \%)$ patients had operative time of 80-100 minutes and 18 (45\%) patients had operative time of 100-120 minutes. The mean operative time was 97.25 mins. The operative time of patients in the study of Ha et al. ${ }^{17}$

There were complications in 4 patients. 1 (2.5\%) patient had limb length shortening by $1.5 \mathrm{cms}, 1(2.5 \%)$ patient had non-union and restriction of movement, $1(2.5 \%)$ patient had delayed union and $1(2.5 \%)$ patient had deformity ER and valgus deformity. Brumback et al in their study had $1 \mathrm{~cm}$ shortening in 2 patients and 1 patient had $2 \mathrm{~cm}$ shortening. ${ }^{18}$ All were due to intraoperative fixation in a shortened position and not due to postoperative loss of fixation.

\section{Final outcome according to Thoresen's criteria ${ }^{19}$}

For evaluation of results in our study Thoresen classification system was used. $55 \%$ patients had excellent results with full, pain-free, function of the extremity, $27.5 \%$ patients had good result, $12.5 \%$ patients had fair 
result and $2.5 \%$ patient had poor result. Thoresen et al reported $63.8 \%$ excellent results, $17 \%$ good results, $15 \%$ fair results and $4.25 \%$ poor results. ${ }^{19}$

Our study had few limitations as surgeons are accustomed for operating femoral shaft fracture in supine position on fracture table whereas in lateral decubitus position intra operative orientation of anatomy and c-arm images is difficult and has a longer learning curve. Additional assistant is required for constant traction and maintaining reduction throughout the procedure, this problem can be overcomed with use of femoral distractor.

\section{CONCLUSION}

In lateral decubitus position the access to the proximal femur was enhanced and making it easy to establish an entry point for an intramedullary device and it significantly eliminates the complications caused by other conventionally used methods .The hip is typically flexed during the nailing, which allows the nail to be placed posterior to the gluteus medius, thus minimizing abductor damage. Operating in lateral decubitus position significantly decreases operative time, fluoroscopy time and blood loss which further helps in early mobilization and weight bearing also allows resumption of knee range of movement exercises at early stage; so it is possible to give good knee range of movement at the end with decreased hospital stay.

With correct anatomical knowledge and proper positioning, preoperative planning and maintaining the reduction during nail insertion and confirming the rotational alignment, before fixing the interlocking bolts to avoid malrotation using AO principles, aseptic precaution, post-operative physiotherapy and counselling of the patient, diaphyseal femur fractures treated with intramedullary interlocking nail in lateral decubitus position gives excellent results.

Funding: No funding sources

Conflict of interest: None declared

Ethical approval: The study was approved by the institutional ethics committee

\section{REFERENCES}

1. Arpacioğlu MO, Akmaz I, Mahiroğullari M, Kiral A, Rodop O. Treatment of femoral shaft fractures by interlocking intramedullary nailing in adults. Acta Orthop Traumatol Turc. 2003;37(3):203-12.

2. Winquist RA, Hansen ST, Clawson DK. Closed intramedullary nailing of femoral fractures. A report of five hundred and twenty cases. J Bone Joint Surg Am. 1984;66:529-39.

3. Weil YA, Gardner MJ, Helfet DL, Pearle AD. Computer navigation allows for accurate reduction of femoral fractures. Clin Orthop Relat Res. 2007;460:185-91
4. Anglen J, Banovetz J. Compartment syndrome in the well leg resulting from fracture table positioning. Clin Orthop Relat Res. 1994;301:239-42.

5. Brumback RJ, Ellison TS. Pudendal nerve palsy complicating intramedullary nailing of the femur. J Bone Joint Surg Am. 1992;74(10):1450-55.

6. Callanan I, Choudhry V, Smith H. Perineal sloughing as a result of pressure necrosis from the traction post during prolonged bilateral femoral nailing. Injury. 1994;25(7):472.

7. Aiyer S, Jagiasi J, Argekar H, Sharan S, Dasgupta B. Closed antegrade interlocked nailing of femoral shaft fractures operated up to 2 weeks post injury in the absence of a fracture table or c-arm. J Trauma. 2006;61:457-60.

8. Liu HT, Wang IC, Yu CM, Huang JW, Wang KC, Chen $\mathrm{CH}$, Ueng SW. Closed femoral nailing in lateral decubitus position without a fracture table: a preliminary report of fifteen patients. Chang Gung Med J. 2005;28(9):629-35.

9. McFerran MA, Johnson KD. Intramedullary nailing of acute femoral shaft fractures using manual traction without a fracture table. J Orthop Trauma. 1995;9:5762.

10. Liao JC, Hsieh PH. Mini open intramedullary nailing of acute femoral shaft fracture: reduction through a small incision without a fracture table. Chang Gung Med J. 2003;26(9):660-8.

11. Stephen DJ, Kreder HJ, Schemitsch EH, Conlan LB, Wild L, McKee MD. Femoral intramedullary nailing: comparison of fracture-table and manual traction. a prospective, randomized study. J Bone Joint Surg Am. 2002;84(9):1514-21.

12. Tornetta P, Ritz G, Kantor A. Femoral torsion after interlocked nailing of unstable femoral fractures. J Trauma. 1995;38:213-9.

13. Johnson KD, Greenberg M. Comminuted femoral shaft fractures. Orthop Clin North Am. 1987;18(1):133-47.

14. Deepak MK, Jain K, Rajamanya KA, Gandhi PR, Rupakumar CS, Ravishankar R. Functional outcome of diaphyseal fractures of femur managed by closed intramedullary interlocking nailing in adults. Ann Afr Med. 2012;11(1):52-7.

15. Klemm KW, Borner $\mathrm{M}$. Interlocking nailing of complex fractures of the femur and tibia. Clin Orthop Relat Res. 1986;212:89-100.

16. White GM, Healy WL, Brumback RJ, Burgess AR, Brooker AF. The treatment of fractures of the femoral shaft with the Brooker-Wills distal locking intramedullary nail. J Bone Joint Surg Am. 1986;68(6):865-76.

17. Ha SH, Kim WH, Lee GC. Results of intramedullary nailing of femoral shaft fracture trochanteric entry portal versus piriformis entry portal (M/DN nail). J Korean Fract Soc. 2014;27(1):50-7.

18. Blumberg KD, Foster WC, Blumberg JF. A comparison of Brooker Wills \&Russel Taylor nails for treatment of fracture femoral shaft. J Bone Joint Surg Am. 1990;72A:1019-24. 
19. Thoresen BO, Alho A, Ekeland A, Strømsøe K, Follerås G, Haukebø A. Interlocking intramedullary nailing in femoral shaft fractures. A report of fortyeight cases. J Bone Joint Surg Am. 1985;67(9):131320.
Cite this article as: Haque SSM, Pathan AA, Aziz AMA, Saba A. Clinical evaluation of diaphyseal femoral fractures operated in lateral decubitus position with interlocking nail. Int J Res Orthop 2021;7:1110-6. 